\title{
Weight Phenotype Diagnostic Test Method: Body Mass Index or Body Fat Percent for Gene Expression
}

\author{
Virginia Lynn Peterson ${ }^{1}$, Angela C. Martino ${ }^{1}$, Arseima Y. Del Valle-Pinero ${ }^{1}$, Nayan S. Patel ${ }^{1}$, \\ Xiongce Zhao ${ }^{2}$, Wendy A. Henderson ${ }^{1 *}$ \\ ${ }^{1}$ National Institute of Nursing Research, National Institutes of Health, Bethesda, MD, USA \\ ${ }^{2}$ National Institute of Diabetes and Digestive and Kidney Diseases, National Institutes of Health, Bethesda, MD, USA
}

\begin{abstract}
Obesity continues increasing at epidemic levels worldwide, as does the number of genetic studies that focus on obesity. Body mass index (BMI) is often used to characterize weight phenotypes and obesity status due to its simplicity. Refined measurements of body composition may be needed to understand variations in gene expression. This study explores gene expression when individuals are characterized as overweight based on BMI versus body fat percent. Individuals were recruited to a natural history protocol at the National Institutes of Health. Twelve Caucasian participants with the highest and lowest BMI were included. Whole-body air displacement plethysmography was performed to calculate body fat percent, and BMI was calculated. Fasting whole blood was collected and RNA extracted. Quantitative real time PCR array was used to determine expression of 96 obesity related genes. The PCR array from participants with high BMI compared to low BMI showed dysregulation of four genes: peroxisome proliferator-activated receptor gamma coactivator 1-alpha (PPARGC1A), pro-opiomelanocortin $(P O M C)$, growth hormone secretagogue receptor (GHSR), and leptin $(L E P)$, whereas participants with high body fat compared to low body fat showed dysregulation of one gene: PPARGC1A. This research showed differential gene expression and clinical indices depending on method of weight classification.
\end{abstract}

Keywords: Body composition, BMI, genetics, methodology, obesity.

\section{INTRODUCTION}

Obesity rates continue to rise worldwide and negatively impact health [1]. According to the American Heart Association, modifiable risk factors associated with cardiovascular disease include obesity, high blood cholesterol, elevated blood pressure, sedentary lifestyle, smoking, and diabetes [2]. As the epidemic increases, the number of genetic studies focusing on obesity risk, associated cardiovascular and endocrine risk factors are abounding [3]. Body mass index (BMI) is commonly used to quantify anthropometrics and identify individuals at risk due to its simplicity [4]. Current studies that use BMI as a standard for defining weight phenotypes and cardiovascular risk are limited in that body composition (lean muscle mass and fat mass), age, and gender are not taken into consideration $[5,6]$. Individuals are considered overweight if they have a BMI $\geq 25$ regardless of gender or body composition. More accurate weight classification methods, including underwater weighing, computed tomography scans, and whole-body air displacement plethysmography calculate lean and fat mass and differentiates by gender in that greater than $25 \%$ body fat is high for males and greater than $30 \%$ is high for females [4]. These refined classify-

*Address correspondence to this author at the Biobehavioral Unit Intramural Research Program NINR, NIH, DHHS Building 10, 2-1339 Bethesda, MD 20892, USA; Tel: 301-451-9534; Fax: 301-480-4889;

E-mail: hendersw@mail.nih.gov cations of body composition, when compared to using BMI, may give varying results when studying gene expression associated with obesity. The aim of the study was to compare differences in gene expression when phenotyping patients based on BMI compared to body fat percent.

\section{METHODS AND PROCEDURES}

\section{Sample}

Participants were recruited to an ongoing natural history protocol at the National Institutes of Health (Clinicaltrial.gov \# NCT00824941), Hatfield Clinical Center from January 2009 to July 2010. A total of twelve participants, with the highest and lowest BMI for genders combined, were selected and included in the analysis with a mean age $25.8 \pm 6.1$ years (range 14-37), 50\% male, and $100 \%$ Caucasian. The participants were then grouped as high BMI $(\geq 25)$ or low BMI ( $\geq 18.5$ and $<25)$. Separately, participants were grouped for the comparative analysis as high body fat (males $\geq 25 \%$, females $\geq 30 \%$ ) or low body fat (males $<25 \%$, females $<30 \%$ ) (Fig. 1).

\section{Data Collection}

Age, gender, and race were collected using the Sociodemographic Questionnaire developed by the Center for Research in Chronic Disorders, University of Pittsburgh School of Nursing (1999) and administered through the Clinical Trials Database. Additional clinical data were collected from the Clinical Research Information System. 


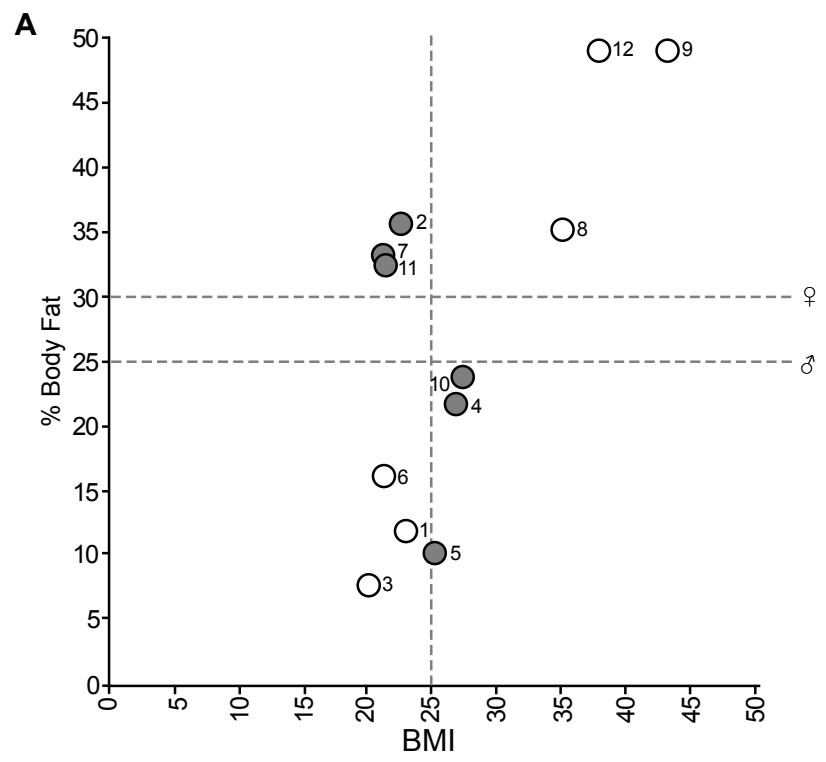

B

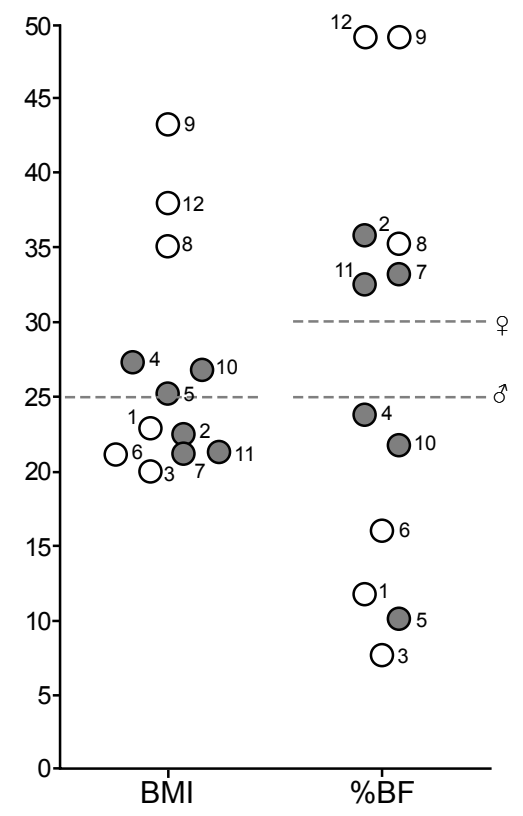

Fig. (1). Weight classification of sample.

A. SHADED circles depict participants who are classified differently depending on weight phenotype grouping method.

B. Depicts actual groupings for data analysis of high/low BMI and high/low body fat percent with gender appropriate thresholds. Shaded circles depict participants who are classified differently depending on weight phenotype grouping method.

Weight was measured in triplicate then averaged, and height was measured in duplicate then averaged. The average height and weight were used to determine BMI, calculated as weight in kilograms divided by height in meters squared. A trained registered nurse completed whole-body air displacement plethysmography (BOD $\mathrm{POD}^{\mathrm{TM}}$ ) on all patients, which determines body fat percent. Intra-abdominal height, a measure from the highest abdominal point to the spine in centimeters while the patient is supine, was calculated via ultrasound. Intra-abdominal height is measured without applying pressure to the ultrasound probe [7]. Venous blood samples were collected in PAXgene ${ }^{\mathrm{TM}}$ RNA tubes the morning after an overnight fast and frozen at $-80^{\circ} \mathrm{C}$. Blood was also sent to the Department of Laboratory Medicine to evaluate routine cardiovascular laboratory values including fasting glucose, total cholesterol, triglycerides, high density lipoprotein (HDL), low density lipoprotein (LDL), and serum insulin.

\section{RNA Extraction and Real-Time PCR}

PAXgene tubes were thawed overnight after which RNA was extracted according to manufacturer's instruction using a PAXgene ${ }^{\mathrm{TM}}$ blood miRNA kit (Qiagen, Franklin Lakes, $\mathrm{NJ}$ ) and normalized to $300 \mathrm{ng}$. RNA integrity was verified using RNA Experion StdSens Analysis Kit. Quantitative real-time PCR array ( $\mathrm{RT}^{2}$ Profiler ${ }^{\mathrm{TM}} \mathrm{PCR}$ Array) was used to determine gene expression in 84 genes related to obesity (Table 1) after cDNA was reverse transcribed using the $\mathrm{RT}^{2}$ First Strand Kit (SA Biosciences by Qiagen, Frederick, MD).

\section{Statistical Analysis}

Clinical and demographic data were analyzed using SPSS version 15.0 (SPSS Inc., Chicago, Illinois). Data are presented as mean \pm standard deviation. Normality of data was assessed and group differences were determined by independent sample t-test for equality of means. A $p$-value of less than 0.05 was considered statistically significant. Genetic data were analyzed using SABiosciences $\mathrm{RT}^{2}$ Profiler $^{\mathrm{TM}}$ Web-Based PCR Array Data Analysis (http://www.sabiosciences.com). Threshold cycle (Ct) cutoff values were set to a maximum of 35 cycles. The formula for a fold change in gene expression was defined as $2^{\wedge}(-$ Delta Delta $\mathrm{Ct}$ ) with normalized test group gene expression values $\left[2^{\wedge}(\right.$-Delta $\left.\mathrm{Ct})\right]$ divided by the normalized control group $\left[2^{\wedge}(-\right.$ Delta $\left.\mathrm{Ct})\right]$. Positive values indicate an upregulation and negative values indicate a down-regulation in gene expression. The fold-change boundary was set at 2 [8].

\section{RESULTS}

When patients were grouped based on BMI there were significant differences between low BMI and high BMI with regard to BMI $(p=0.004)$, intra-abdominal height $(p=$ $0.009)$, systolic blood pressure (SBP) $(p=0.017)$, and HDL $(p=0.010)$; there were no significant differences between the groups with regard to age, gender, race, body fat percent, diastolic blood pressure (DBP), glucose, cholesterol, triglycerides, LDL, or serum insulin (Table 2). When patients were grouped based on body fat percent there were significant differences between low body fat and high body fat with regard to gender $(p=0.021)$, body fat percent $(p<$ $0.001)$, total cholesterol $(p=0.003)$, triglycerides $(p=$ $0.009)$, LDL $(p=0.007)$, and serum insulin $(p=0.041)$; there were no significant differences between the groups with regard to age, race, BMI, intra-abdominal height, SBP, DBP, glucose, or HDL (Table 2). Note that certain individuals with a high BMI did not have high body fat percent and therefore were grouped differently as seen in Fig. (1)(e.g., ID \#4, 5, and 10). Likewise individuals with low BMI had high body fat (e.g., ID \# 2, 7, and 11). 
Table 1. Human Obesity Gene Array

\begin{tabular}{|c|c|c|c|c|c|c|c|c|c|c|c|c|}
\hline & $\mathbf{1}$ & $\mathbf{2}$ & $\mathbf{3}$ & $\mathbf{4}$ & $\mathbf{5}$ & $\mathbf{6}$ & $\mathbf{7}$ & $\mathbf{8}$ & $\mathbf{9}$ & $\mathbf{1 0}$ & $\mathbf{1 1}$ & $\mathbf{1 2}$ \\
\hline \hline A & ADCYAP1 & ADCYAP1R1 & ADIPOQ & ADIPOR1 & ADIPOR2 & ADRA2B & ADRB1 & AGRP & APOA4 & ATRN & BDNF & BRS3 \\
\hline B & C3 & CALCA & CALCR & CARTPT & CCK & CCKAR & CLPS & CNR1 & CNTFR & CPD & CPE & CRHR1 \\
\hline C & DRD1 & DRD2 & GAL & GALR1 & GCG & GCGR & GH1 & GH2 & GHR & GHRL & GHSR & GLP1R \\
\hline D & GRP & GRPR & HCRT & HCRTR1 & HRH1 & HTR2C & IAPP & IL1A & IL1B & IL1R1 & IL6 & IL6R \\
\hline E & INS & INSR & LEP & LEPR & MC3R & MCHR1 & NMB & NMBR & NMU & NMUR1 & NPY & NPY1R \\
\hline F & NR3C1 & NTRK2 & NTS & NTSR1 & OPRK1 & OPRM1 & POMC & PPARA & PPARG & PPARGC1A & PRLHR & PTPN1 \\
\hline G & PYY & RAMP3 & SIGMAR1 & SORT1 & SST & SSTR2 & THRB & TNF & TRH & UCN & UCP1 & ZFP91 \\
\hline H & B2M & HPRT1 & RPL13A & GAPDH & ACTB & HGDC & RTC & RTC & RTC & PPC & PPC & PPC \\
\hline
\end{tabular}

ADCYAP1 = Adenylate cyclase activating polypeptide 1 (pituitary), ADCYAP1R1 = Adenylate cyclase activating polypeptide 1 (pituitary) receptor type I, ADIPOQ = Adiponectin, $\mathrm{C} 1 \mathrm{Q}$ and collagen domain containing, $\mathrm{ADIPOR} 1=$ Adiponectin receptor 1 , ADIPOR2 = Adiponectin receptor 2, ADRA2B = Adrenergic, alpha-2B-, receptor, ADRB1 = Adrenergic, beta-1-, receptor, AGRP = Agouti related protein homolog (mouse), APOA4 = Apolipoprotein A-IV, ATRN Attractin, BDNF = Brain-derived neurotrophic factor, BRS3 = Bombesin-like receptor 3, C3 = Complement component 3, CALCA $=$ Calcitonin-related polypeptide alpha, CALCR $=$ CALCITONIN RECEPTOR, CARTPT = CART prepropeptide, $\mathrm{CCK}=$ Cholecystokinin, CCKAR $=$ Cholecystokinin A receptor, CLPS $=$ Colipase, pancreatic, CNR1 = Cannabinoid receptor 1 (brain), CNTFR = Ciliary neurotrophic factor receptor, CPD = Carboxypeptidase D,CPE = Carboxypeptidase E, CRHR1 = Corticotropin releasing hormone receptor 1, DRD1= Dopamine receptor D1, DRD2 = Dopamine receptor D2, GAL = Galanin prepropeptide, GALR1 $=$ Galanin receptor 1, GCG $=$ Glucagon, GCGR $=$ Glucagon receptor, GH1 = Growth hormone 1 , GH2 = Growth hormone 2, GHR = Growth hormone receptor, GHRL $=$ Ghrelin/obestatin prepropeptide, GHSR $=$ Growth hormone secretagogue receptor, GLP1R $=$ Glucagon-like peptide 1 receptor, GRP = Gastrin-releasing peptide, GRPR = Gastrin-releasing peptide receptor, HCRT = Hypocretin (orexin) neuropeptide, HCRTR1 = Hypocretin (orexin) receptor 1, HRH1 $=$ Histamine receptor H1, HTR2C = 5-hydroxytryptamine (serotonin) receptor IAPP = Islet amyloid polypeptide, IL1A = Interleukin 1, alpha, IL1B = Interleukin 1, beta, IL1R1 = Interleukin 1 receptor, type I, IL6 = Interleukin 6 , IL6R $=$ Interleukin 6 receptor, INS $=$ Insulin, INSR $=$ Insulin receptor, LEP $=$ Leptin, LEPR $=$ Leptin receptor,MC3R $=$ Melanocortin 3 receptor, MCHR1 = Melanin-concentrating hormone receptor 1 , NMB Neuromedin B, NMBR $=$ Neuromedin B receptor, NMU = Neuromedin U, NMUR1 = Neuromedin U receptor $1, \mathrm{NPY}=$ Neuropeptide Y, NPY1R = Neuropeptide Y receptor Y1, NR3C1 = Nuclear receptor subfamily 3, group C, member 1 (glucocorticoid receptor), NTRK2 = Neurotrophic tyrosine kinase, receptor, type 2, NTS = Neurotensin, NTSR1 = Neurotensin receptor 1 (high affinity), OPRK1 = Opioid receptor, kappa 1, OPRM1 = Opioid receptor, mu 1, POMC $=$ Proopiomelanocortin, PPARA $=$ Peroxisome proliferator-activated receptor alpha, PPARG $=$ Peroxisome proliferator-activated receptor gamma PPARGC1A = Peroxisome proliferator-activated receptor gamma, coactivator 1 alpha, PRLHR = Prolactin releasing hormone receptor, PTPN1 = Protein tyrosine phosphatase, PYY = Peptide YY, RAMP3 = Receptor $(\mathrm{G}$ protein-coupled $)$ activity modifying protein 3 , SIGMAR1 = Sigma non-opioid intracellular receptor 1 , SORT1 = Sortilin 1 , SST $=$ Somatostatin, SSTR2 $=$ Somatostatin receptor 2, THRB $=$ Thyroid hormone receptor, beta (erythroblastic leukemia viral $(v-e r b-a)$ oncogene homolog 2, avian), TNF $=$ Tumor necrosis factor, TRH = Thyrotropin-releasing hormone, UCN = Urocortin, UCP1 = Uncoupling protein 1 (mitochondrial, proton carrier), ZFP91 = Zinc finger protein 91 homolog (mouse), B2M = Beta-2-microglobulin, HPRT1 = Hypoxanthine phosphoribosyltransferase 1, RPL13A = Ribosomal protein L13a, GAPDH = Glyceraldehyde-3-phosphate dehydrogenase, $\mathrm{ACTB}=$ Actin, beta, HGDC $=$ Human Genomic DNA Contamination, RTC $=$ Reverse Transcription Control, RTC $=$ Reverse Transcription Control, RTC $=$ Reverse Transcription Control, PPC $=$ Positive PCR Control, PPC $=$ Positive PCR Control, PPC $=$ Positive PCR Control

Table 2. Sample Characteristics Classified Based on Body Fat Percent and BMI

\begin{tabular}{|c|c|c|c|c|c|c|c|}
\hline Variable & $\begin{array}{l}\text { Overall } \\
(N=12)\end{array}$ & $\begin{array}{l}\text { High Body Fat } \\
\qquad(n=6)\end{array}$ & $\begin{array}{l}\text { Low Body Fat } \\
\qquad(n=6)\end{array}$ & $p$-Value & $\begin{array}{l}\text { High BMI } \\
\quad(n=6)\end{array}$ & $\begin{array}{c}\text { Low BMI } \\
\quad(n=6)\end{array}$ & $p$-Value \\
\hline & $\mathrm{n} / \mathrm{M} \pm \mathrm{SD}$ & $\mathrm{n} / \mathrm{M} \pm \mathrm{SD}$ & $\mathrm{n} / \mathrm{M} \pm \mathrm{SD}$ & t-test & $\mathrm{n} / \mathrm{M} \pm \mathrm{SD}$ & $\mathrm{n} / \mathrm{M} \pm \mathbf{S D}$ & t-test \\
\hline $\begin{array}{c}\text { Age } \\
\text { Median (range years) }\end{array}$ & $\begin{array}{l}25.83 \pm 6.12 \\
24(14-37)\end{array}$ & $\begin{array}{l}27.67 \pm 6.02 \\
27(22-37)\end{array}$ & $\begin{array}{c}24.0 \pm 6.16 \\
23.5(14-31)\end{array}$ & 0.322 & $\begin{array}{l}25.83 \pm 8.11 \\
26(14-37)\end{array}$ & $\begin{array}{l}25.83 \pm 4.07 \\
24(22-31)\end{array}$ & 1.0 \\
\hline $\begin{array}{l}\text { Gender (n) } \\
\text { Male }\end{array}$ & 6 & 1 & 5 & $0.080^{\mathrm{d}}$ & 4 & 2 & $0.567^{\mathrm{d}}$ \\
\hline $\begin{array}{c}\text { Race }(n) \\
\text { Caucasian }\end{array}$ & 12 & 6 & 6 & - & 6 & 6 & - \\
\hline $\operatorname{BMI}\left(\mathrm{kg} / \mathrm{m}^{2}\right)$ & $27.02 \pm 7.60$ & $30.16 \pm 9.73$ & $23.88 \pm 2.97$ & 0.161 & $32.54 \pm 7.27$ & $21.50 \pm 1.06$ & $0.004^{\mathrm{b}}$ \\
\hline Body Fat (\%) & $27.18 \pm 14.24$ & $39.13 \pm 7.81$ & $15.23 \pm 6.50$ & $<0.001^{\mathrm{c}}$ & $31.53 \pm 15.75$ & $22.83 \pm 12.35$ & 0.312 \\
\hline Intra-abdominal height $(\mathrm{cm})$ & $9.96 \pm 2.79$ & $11.12 \pm 3.24$ & $8.80 \pm 1.84$ & 0.160 & $11.87 \pm 2.57$ & $8.05 \pm 1.35$ & $0.009^{\mathrm{b}}$ \\
\hline $\mathrm{SBP}(\mathrm{mm} \mathrm{Hg})$ & $119.5 \pm 16.34$ & $116.33 \pm 15.88$ & $122.67 \pm 17.63$ & 0.528 & $130.0 \pm 14.66$ & $109.0 \pm 10.37$ & $0.017^{\mathrm{a}}$ \\
\hline $\mathrm{DBP}(\mathrm{mm} \mathrm{Hg})$ & $72.08 \pm 8.33$ & $71.50 \pm 6.09$ & $72.67 \pm 10.71$ & 0.821 & $76.0 \pm 8.81$ & $68.17 \pm 6.18$ & 0.105 \\
\hline Glucose (mg/dL) & $87.42 \pm 5.28$ & $86.83 \pm 6.31$ & $88.0 \pm 4.56$ & 0.721 & $89.17 \pm 2.86$ & $85.67 \pm 6.77$ & 0.271 \\
\hline Total chol (mg/dL) & $172.0 \pm 31.53$ & $195.50 \pm 25.38$ & $148.50 \pm 14.72$ & $0.003^{\mathrm{b}}$ & $163.83 \pm 27.66$ & $180.17 \pm 35.52$ & 0.395 \\
\hline Triglycerides (mg/dL) & $105.08 \pm 51.83$ & $140.50 \pm 36.03$ & $69.67 \pm 40.0$ & $0.009^{\mathrm{b}}$ & $91.50 \pm 53.59$ & $118.67 \pm 50.93$ & 0.389 \\
\hline HDL chol (mg/dL) & $53.25 \pm 13.20$ & $54.17 \pm 18.41$ & $52.33 \pm 6.50$ & 0.823 & $44.33 \pm 8.52$ & $62.17 \pm 10.94$ & $0.010^{\mathrm{b}}$ \\
\hline LDL chol (mg/dL) & $97.75 \pm 22.17$ & $113.17 \pm 18.43$ & $82.33 \pm 13.08$ & $0.007^{\mathrm{b}}$ & $101.33 \pm 24.07$ & $94.17 \pm 21.70$ & 0.600 \\
\hline Serum Insulin $(\mathrm{mcU} / \mathrm{mL})$ & $8.93 \pm 8.26$ & $13.70 \pm 9.70$ & $4.27 \pm 1.62$ & $0.041^{\mathrm{a}}$ & $12.60 \pm 10.45$ & $5.37 \pm 3.11$ & 0.135 \\
\hline
\end{tabular}

Note. BMI, body mass index; SBP, systolic blood pressure; DBP, diastolic blood pressure; chol, cholesterol; HDL, high-density lipoprotein; LDL, low-density lipoprotein; ${ }^{\mathrm{a}} \mathrm{P}<.05$, ${ }^{\mathrm{b}} \mathrm{P}<.01,{ }^{\mathrm{c}} \mathrm{P}<.001 .{ }^{\mathrm{d}}$ Fisher's Exact. 

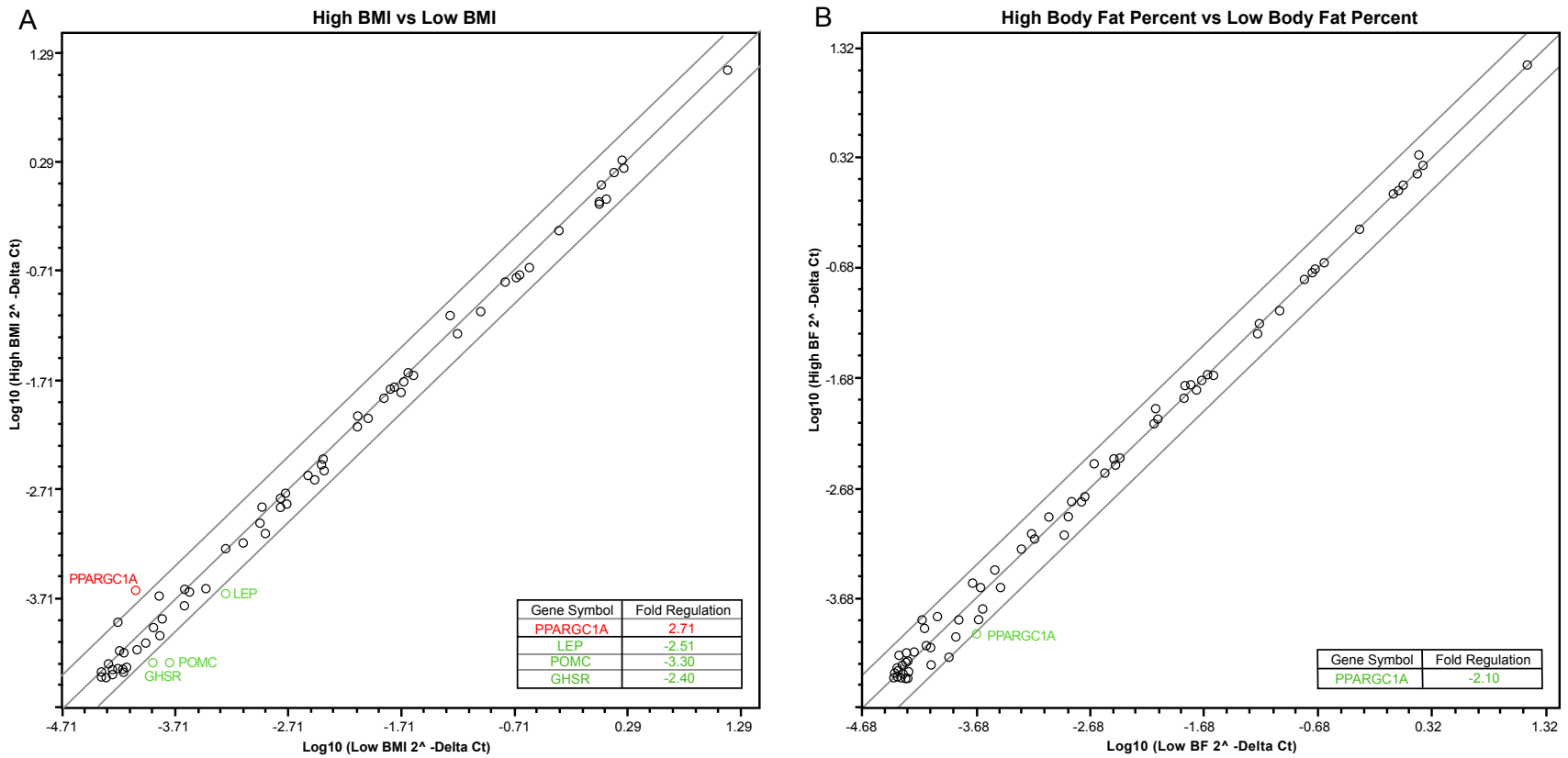

Fig. (2). Gene expression based on differential weight phenotype classification.

A. High BMI verses low BMI.

B. High body fat percent verses low body fat percent.

Note. Peroxisome proliferator-activated receptor gamma coactivator 1-alpha (PPARGC1A), leptin (LEP), pro-opiomelanocortin (POMC), growth hormone secretagogue receptor (GHSR).

The PCR array from patient samples with high BMI compared to low BMI showed dysregulation in four of the 84 genes: peroxisome proliferator-activated receptor gamma coactivator 1-alpha (PPARGC1A, 2.71-fold, $p=0.103)$, proopiomelanocortin (POMC, -3.30-fold, $p=0.316$ ), growth hormone secretagogue receptor $(G H S R,-2.40$-fold, $p=$ 0.056 ), and leptin ( $L E P,-2.51$-fold, $p=0.135$ ) (Fig. 2). The PCR array from patient samples with high body fat compared to low body fat showed dysregulation in only one gene: PPARGC1A (-2.10-fold, $p=0.650)$ (Fig. 2).

\section{DISCUSSION}

The findings included significant differences in four genes (PPARGC1A, POMC, GHSR, and LEP) when altering the weight phenotype classification method [9-15]. Due to the simplicity and convenience of BMI, seeing similar gene expression patterns regardless of BMI or body fat classification would be ideal. However, the aforementioned results are contradictory with variations in both gene expression and clinical indices related to grouping based on BMI verses body fat percent. Differences in gene expression were found when grouping individuals based on BMI and body fat. Individuals grouped by a high body fat when compared to controls (low body fat) showed dysregulation in one gene (PPARGCIA). Whereas, grouping individuals based on high BMI when compared to controls (low BMI) showed dysregulation in four genes (PPARGC1A, POMC, $G H S R, L E P)$. Specifically, an absence of leptin has been shown to activate the $P O M C$ signaling cascade which leads to decreased food intake and increased energy expenditure $[12,14]$. Additionally, PPARGC1A has also been shown to be critical in energy metabolism due to its increased expression in tissues with high-oxidative capacity such as muscle fibers and brown adipose tissue [15].

Obesity continues to be a strong determinant for cardiovascular disease; however there are many methods of determining an individual's weight classification. Our data show that when characterizing by body fat percent clinical indices mirror cardiovascular risk factors more appropriately than when characterizing by BMI. When grouping according to body fat percent the cardiovascular risk factors including elevated total cholesterol, triglycerides, LDL, and serum insulin are evident. Comparatively, elevated systolic blood pressure and HDL were noted when the sample was classified based on BMI. There were clear and significant differences in the pattern of modifiable cardiovascular risk factors based on method of weight classification.

Limitations of this study include a small sample size and additionally, the effects of ethnicity were not considered. Although the overall sample controlled for gender and race, the results may be confounded by percent fat differences between the genders. Confirmation of these findings in a larger cohort is warranted.

In summary, this research showed there are differences when characterizing an individual based on BMI and body fat percent including areas of genetic expression and clinical indices. Not only might low risk individuals be inadvertently misclassified but also those at high cardiovascular risk, due to high body fat, may be missed. Therefore, using only BMI clinically and genetically may not be enough to accurately determine individual risk. Special attention should be considered when phenotyping to determine an individual's cardiovascular risk. 


\section{ACKNOWLEDGEMENTS}

The authors would like to thank the participants of the study, as well as the staff from the NIH Clinical Center, in particular Dr. Kong Chen and the NIDDK Metabolic Program of Care. The authors would like to thank the University of Pittsburgh School of Nursing for use of the Socio-demographic Questionnaire (1999); Center for Research in Chronic Disorders (P30 NR003924).

\section{CONFLICT OF INTEREST}

All of the authors have no potential conflicts of interest to disclose. Note: The opinions expressed herein and the interpretation and reporting of these data are the responsibility of the author(s) and in no way should be seen as an official recommendation, interpretation, or policy of the National Institutes of Health or the US Government.

\section{AUTHOR CONTRIBUTORSHIP}

All of the authors have approved the final draft of the manuscript submitted. All authors contributed to the analysis and writing of the manuscript. Dr. Henderson devised the study and wrote the protocol.

\section{FUNDING}

The study was supported by funding from the US Department of Health and Human Services, National Institutes of Health, National Institute of Nursing Research Intramural Research Program (to W.A.H., 1ZIANR00001801/02; Intramural Training Awards to A.Y.D., and N.S.P.; Summer Internship Award to V.L.P.).

\section{ETHICS APPROVAL}

The protocol (09-NR-0064) was approved by the Institutional Review Board at the National Institutes of Health. Clinicaltrial.gov \# NCT00824941.

\section{DATA SHARING}

Dataset available through the corresponding author hendersw@ mail.nih.gov one year following publication.

\section{REFERENCES}

[1] Caballero B. The global epidemic of obesity: an overview. Epidemiol Rev 2007; 29: 1-5.

[2] Grundy SM, Cleeman JI, Daniels SR, et al. Diagnosis and management of the metabolic syndrome: an American Heart Association/National Heart, Lung, and Blood Institute Scientific Statement. Circulation 2005; 112: 2735-52.

[3] Chung WK, Leibel RL. Considerations regarding the genetics of obesity. Obesity (Silver Spring) 2008; 16(Suppl 3): S33-9.

[4] Bergman RN, Stefanovski D, Buchanan TA, et al. A better index of body adiposity. Obesity (Silver Spring) 2011; 19: 1083-9.

[5] Gomez-Ambrosi J, Silva C, Galofre JC, et al. Body adiposity and type 2 diabetes: increased risk with a high body fat percentage even having a normal BMI. Obesity (Silver Spring) 2011; 1439-44.

[6] Romero-Corral A, Somers VK, Sierra-Johnson J, et al. Accuracy of body mass index in diagnosing obesity in the adult general population. Int J Obes (Lond) 2008; 32: 959-66.

[7] De Lucia RE, Sleigh A, Finucane FM, et al. Ultrasound measurements of visceral and subcutaneous abdominal thickness to predict abdominal adiposity among older men and women. Obesity (Silver Spring) 2010; 18: 625-31.

[8] McCarthy DJ, Smyth GK. Testing significance relative to a foldchange threshold is a TREAT. Bioinformatics 2009; 25: 765-71.

[9] Garcia EA, Heude B, Petry CJ, et al. Ghrelin receptor gene polymorphisms and body size in children and adults. J Clin Endocrinol Metab 2008; 93: 4158-61.

[10] Hixson JE, Almasy L, Cole S, et al. Normal variation in leptin levels in associated with polymorphisms in the proopiomelanocortin gene, POMC. J Clin Endocrinol Metab 1999; 84: 3187-91.

[11] Speliotes EK, Willer CJ, Berndt SI, et al. Association analyses of 249,796 individuals reveal 18 new loci associated with body mass index. Nat Genet 2010; 42: 937-48.

[12] Suviolahti E, Ridderstrale M, Almgren P, et al. Proopiomelanocortin gene is associated with serum leptin levels in lean but not in obese individuals. Int J Obes Relat Metab Disord 2003; 27: 1204-11.

[13] Chanoine JP, De Waele K, Walia P. Ghrelin and the growth hormone secretagogue receptor in growth and development. Int $\mathbf{J}$ Obes (Lond) 2009; 33 (Suppl 1): S48-52.

[14] Krude H, Biebermann H, Schnabel D, et al. Obesity due to proopiomelanocortin deficiency: three new cases and treatment trials with thyroid hormone and ACTH4-10. J Clin Endocrinol Metab 2003; 88: 4633-40.

[15] Ma D, Li S, Lucas EK, Cowell RM, Lin JD. Neuronal inactivation of peroxisome proliferator-activated receptor gamma coactivator 1alpha (PGC-1alpha) protects mice from diet-induced obesity and leads to degenerative lesions. J Biol Chem 2010; 285: 39087-95.

\footnotetext{
Received: January 30, 2012 Revised: June 30, 2012 Accepted: July 07, 2012

(C) Peterson et al.; Licensee Bentham Open.

This is an open access article licensed under the terms of the Creative Commons Attribution Non-Commercial License (http://creativecommons.org/licenses/by-nc/3.0/) which permits unrestricted, non-commercial use, distribution and reproduction in any medium, provided the work is properly cited.
} 